\title{
A fenomenologia do cuidar: prática dos horizontes vividos nas áreas da saúde, educacional e organizacional
}

\author{
José Maria Montiel
}

Pokladek, D. D. (Org.). (2004). A fenomenologia do cuidar: prática dos horizontes vividos nas áreas da saúde, educacional e organizacional. São Paulo, SP: Vetor, 300 p.

O cuidar do ser humano como foco de atenção nos serviços que prestam assistência a pessoas, como as áreas da saúde, educacional e organizacional, é de suma relevância, estando relacionado às maneiras como profissionais de formações diversas desempenham suas funções e ao respeito pelo ser humano, nos procedimentos adotados, ou às manifestações dirigidas a estes. Com o objetivo de apresentar questões teóricas e práticas a profissionais que têm o cuidar do humano como projeto existencial em suas relações interpessoais, esse livro foi organizado em duas partes. A primeira está relacionada às conferências proferidas durante o 1ㅇ Simpósio do Instituto Psicoethos e a segunda, a experiências terapêticas da equipe do Instituto, viabilizando subsidiar a ação de profissionais que almejam atuar nesta abordagem de maneira digna, ética e humana. Os dados foram organizados a partir de um evento realizado em 2003 pelo Instituto Psicoethos, com o apoio do Sesc de São Paulo, da Universidade Metodista de São Bernardo do Campo, do grupo Fenpec, Instituto Ifen do Rio de Janeiro, Grupo de Pesquisas de Alfred Schutz e do grupo de pesquisa qualitativa da Universidade Sagrado Coração de Bauru, SP.

Em $A$ massificação do bomem e o destino da bumanidade, buscando um jeito fenomenológico de conbecer o mundo, Dalva L. dos Santos e Danuta D. Pokladek abordam conceitos e concepções do ser no mundo, tendo como referencial a fenomenologia, de modo a propiciar compreensão de seu cotidiano, formas de expressões e concepções sobre o existir, fatores que fazem do homem um ser sonhador que busca, por intermédio de sonhos, continuar sua existência, manifestações existenciais, elegendo projetos existenciais. Segundo as autoras, a massificação ocorre quando não se elege um projeto de vida, ocasionando a desconsideração de sua condição entre seus pares, isto é, deixando de cuidar da vida, perdendo a consciência de que ser humano é ter capacidade de construir sua própria história.

No segundo capítulo, A fenomenologia como novo paradigma de uma ciência do existir, Rui de S. Josgrilberg descreve que o esgotamento e o surgimento de novos paradigmas ocasionam os avanços da ciência, desenvolvendo-se novas estruturas da existência e do existir. Assim, a fenomenologia visa buscar, por meio de

\footnotetext{
${ }^{1}$ Endereço para correspondência:
}

E-mail: montieljm@hotmail.com métodos, respostas que fundamentem a preocupação da relação eu-mundo, sendo resultado da ligação entre o que pensamos e expressamos, por meio de métodos casuístas, delimitando investigações dos processos causais, considerando que cada ser humano traz consigo elementos básicos de todo conhecimento. A relação do eu com algo é definida como consciência e o perceber torna-se algo oferecido e aparece como um fenômeno doado, apresentando uma razão natural, gerando pensamentos de objetos e não sujeitos a erros.

Ao se referir sobre a percepção do outro em si mesmo, Creusa Capalbo, no terceiro capítulo, A fenomenologia existencial e a experiência do outro, realça a importância do comportamento expressivo ser entendido, isto é, as expressões intersubjetivas, compreendidas pelos aspectos de linguagem que possibilitam a convivência social, a expressão de afetos e ações, constituindo-se, desta forma, a vida pessoal em comunidade, implicando na compreensão consistente e intersubjetiva.

O quarto capítulo, Abordagem fenomenológica de Alfred Schutz, na enfermagem, escrito por Florence R. Tocantins e Mariana L. Nogueira, aborda a compreensão da prática social como ação intencional nas relações pessoais, visando à existência da promoção de bem-estar e saúde, centrada na concepção estrutural do mundo, de forma contextualizada e individualizada, vivenciando e interpretando fenômenos, de acordo com sua singularidade. As autoras enfatizam as ações voltadas para o ser humano e as inter-relações, por meio do relacionamento social de confiança, da expressão de suas necessidades e anseios, respeitando diferenças sem a existência de julgamentos e conceitos pré-formados.

Marli D. de Oliveira relata, no quinto capítulo, Saúde mental e trabalho: o entendimento da realidade vivida, que o profissional de psicologia no ambiente de trabalho deve propiciar às pessoas escuta de suas experiências, identificando o sentido de suas descrições, favorecendo aspectos de saúde, conhecendo o sentido e a vivência por meio das percepções e sentimentos. Outras observações importantes estão relacionadas às mudanças e reestruturações ocorridas e possíveis neste ambiente. A atuação deve possibilitar formas de atuação, intervenções e reflexões, amenizando desgastes físicos e psíquicos e freqüentes manifestações de promoção de saúde. 
Em $A$ morte - a arte de cuidar na despedida, Mara Villas Boas de Carvalho enfatiza a comunicação como forma de escuta aberta e respeitosa, propiciando dignidade e conforto do paciente em situação de terminalidade, influenciado por angústias e interrogações nas histórias de vida, do presente e de perspectivas futuras. Neste contexto, o ato de cuidar envolve o processo de assistir associado a sentimentos e conhecimentos, amenizando o sofrimento por meio de inter-relações e confiança mútua, baseadas em valores humanitários, técnicos e científicos. A autora relata que a escuta torna-se uma condição de acolhimento e alívio da dor e de sofrimentos; mesmo que a palavra não seja pronunciada existe o sentimento de ser acolhido. Os cuidadores devem considerar a trajetória de vida daqueles a quem prestam assistência e a escuta tende a propiciar qualidade de vida, levando em conta aspectos emocionais, funcionais e psicológicos.

No capítulo Direito à vida $x$ direito atropelado na base. A cidadania das crianças e adolescentes em questão, escrito por Dagmar S. P. de Castro, é descrita a experiência no Conselho Tutelar em um movimento ultrapassando os limites da legislação elaborada em cumprimento ao Estatuto da Criança e do Adolescente (ECA). Segundo a autora, as experiências vivenciadas em instituições de acolhimento de crianças e adolescentes, como a Funabem e as Febems, tiveram significativa importância para ressaltar a necessidade de mecanismos capazes de atender às demandas observadas. O ECA propiciou forte engajamento e comprometimento nas transformações sociais perante um mundo globalizado, uma vez que a maioria dessas pessoas vive em locais onde estão ausentes inúmeros serviços básicos de sobrevivência, descritos como geografia da não-cidadania. As mudanças relativas a este cuidar estão entrelaçadas na subjetividade, permitindo a atuação em diferentes esferas em que crianças e adolescentes vivem, sem deixá-los apenas no discurso de um sistema organizacional de leis e regulamentos. Os aspectos psicológicos devem tornar-se formas mediadoras de instituir novos conhecimentos particularizados, no discurso e nas ações.

A segunda parte deste livro inicia-se com o capítulo de Dalva L. dos Santos, Relato de uma ação psicopedagógica: construindo caminhos para uma prática inclusiva. $O$ contexto, a ação desenvolvida e as perspectivas futuras, que descreve a prática inclusiva como busca pela permanência de alunos no ambiente escolar, de forma a ultrapassar barreiras da não-aprendizagem, enfatizando a criação de estratégias que possibilitem potencialidades e capacidades dos membros envolvidos. O trabalho, por meio de uma ação psicopedagógica, incluiu a observação participativa nas aulas, supervisão dos trabalhos realizados, grupos de estudos, reuniões e encontros com pais de alunos, e entrevistas individuais com esses pais. Assim, o aprender deve estar relacionado às possibilidades e necessidades de cada aluno.

No capítulo seguinte, Danuta D. Pokladek aborda o tema $O$ modo de perceber e de relacionar de uma pessoa portadora de lípus eritematoso sistêmico. Possibilidades e limites de uma atuação fenomenológico-existencial. Destaca a doença lúpus por seu aspecto crônico que afeta o sistema imunológico, comprometendo a pele e articulações de seus portadores, entre outros órgãos, considerada uma importante doença auto-imune de causa desconhecida. A autora destaca que o método fenomenológico pode compreender o ser lúpico, enfatizando que a fenomenologia procura entender a doença como um modo existencial de manifestação e de expressão, percebendo o estado clínico como parte do meio em que a pessoa está inserida, como experiência do corpo vivida. Aponta que a arte do cuidar é dar atenção à pessoa doente, acompanhando, recebendo-a e favorecendo a escuta.

Ser de alguém ou não ser de ninguém. Uma perspectiva fenomenológica existencial é o tema do capítulo no qual Danuta D. Pokladek aponta questões ocasionadas pela época da pós-modernidade - como o crivo do en e a relação $t u$ tornaram-se inexistentes - e referenciadas como a era light, que possibilitam que as pessoas sejam membros de grupos sociais, conhecidas como normalpatas. A autora cita que essa conduta vem ocasionando manifestações de fracassos emocionais. Formas mais adequadas em um relacionamento referem-se a ouvir o próprio coração enquanto ser humano, criando inter-relações mais humanas, com respeito e dignidade.

As autoras Danuta D. Pokladek e Nadima C. Haddad citam no capítulo denominado Mergulhar no mar da bumanidade. Uma reflexão fenomenológico-existencial na prática do profissional da saúde, que os atendimentos realizados por profissionais da área de saúde ocorrem de maneira linear, onde pacientes são tratados como fichas ambulatoriais, números ou nomenclaturas médicas, resultando no aniquilamento do ser pessoa. Apontam divergências nesse tipo de conduta com os pressupostos da fenomenologia, que enfatiza a aproximação da pessoa comprometida, que necessita de cuidados especiais, um ser em que os sentidos e significados estão implícitos. Propõem que os profissionais de saúde enfatizem a relação profissional $\mathrm{x}$ paciente, adequando a comunicação, possibilitando a recolocação do homem em sua condição existencial, compreendendo suas relações e percepções cotidianas.

No Workshop Sensibilização para profissionais da saúde com relação ao cuidar do bumano, Danuta D. Pokladek e Nadima C. Haddad finalizam essa obra com o tema Mergulbar no mar da bumanidade - uma reflexão fenomenológicoexistencial na prática de profissional de saúde e reforçam a importância da escuta nas relações. Apontam que o cuidar do ser humano está envolvido em obterem-se resultados favoráveis.

Psico-USF, v. 9, n. 2, p. 221-223, Jul./Dez. 2004 
Trata-se de um livro muito bem organizado, com temas pertinentes à prática do cuidar, ilustrando questões fundamentais para a compreensão das transformações do homem com referencial ao aspecto natural e gradual dessa evolução, sem que sejam vistos como sintomas e desconsiderando-se a essência deste, isto é, suas experiências, seu contexto, seus sentimentos e aflições. Essa obra, em sua totalidade, oferece experiências e informações às pessoas preocupadas com o cuidar, desvendando o que pequeno a olhos nu e imenso ao considerar-se o homem um ser mutável.

Sobre o autor:

José Maria Montiel é psicólogo, mestrando do Programa de Pós-Graduação Stricto Sensu em Psicologia da Universidade São Francisco. 
